\title{
The challenges of adopting BIM for setting and infrastructure management of University of Minho
}

\author{
Paulo J. S. Cruz ${ }^{1}$, and Miguel Azenha ${ }^{2}$ \\ ${ }^{1}$ Lab2PT, University of Minho, Pro-Rector, 4800-058 Guimarães, Portugal \\ ${ }^{2}$ ISISE, University of Minho, Dep. of Civil Eng., School of Engineering, 4800-058 Guimarães, Portugal
}

\begin{abstract}
The University of Minho (UMinho) is aware of the relevant role of higher education institutions in the global challenge of sustainability. The integration of sustainability values into its strategy encompasses all the fields of its activity. Taking into account the growing importance of shared knowledge resources as a reliable basis for decisions during infrastructures life cycle, the UMinho is currently undergoing an important process of implementing a 'Building Information Modelling' framework (BIM). This paper briefly describes the implementation steps that are current towards such a goal, in particular in terms of facilities management aspects.
\end{abstract}

\section{Introduction}

UMinho is currently one of the most prestigious Portuguese higher education institutions and it is gradually becoming more prominent internationally. It was founded in 1973 and offers a wide range of courses corresponding to first, second and third cycles of studies leading to undergraduate, graduate or doctorate degrees. The UMinho has approximately 20.000 students, 1.300 professors and 900 non-teaching and non-research staff, which represents a population higher than $70 \%$ of the 308 Portuguese municipalities.

The sustainability policy adopted by UMinho is defined in the strategic plan of UMinho 2020. It contains the administration, management, operational management, educational activity, research activities, the dissemination of its performance and its impact which is based on a holistic vision, a fundamental element to ensure life quality levels in the campuses. UMinho's endeavours regarding Environmental, Social, Economic and Cultural dimensions are carried out, on a regular basis, according to the best international practices. This paper should also be, on the one hand, a tool for communicating strategy and the paths taken and an instrument for demonstrating and inducing new behaviours and, on the other hand, a way to promote new partnerships with other institutions that share the same view as UMinho's.

In 2017 the UI GreenMetric World University Ranking awarded the UMinho with the $1^{\text {st }}$ position in Portugal and with the $48^{\text {th }}$ world position among 619 universities from 76 countries. This recognizes UMinho's commitment in developing 'environmentally friendly' infrastructures and a relevant score in the six specific indicators that compose the ranking (setting and

*Corresponding author: peruz@,reitoria.uminho.pt infrastructure, energy and climate change, waste, water, transportation and education).

In line with the sustainability goals stated above, this paper presents the strategic roadmap that the UMinho has established towards a more effective and sustainable process of infrastructure management, through the implementation of 'Building Information Modelling' techniques.

\section{The UMinho infrastructures}

Teaching and research activities take place in the three UMinho campuses: Gualtar Campus (Fig. 1), in the city of Braga, and the Azurém Campus (Fig. 2) and Couros Campus, both in the city of Guimarães.

The Schools of Sciences, Health Sciences, Law, Psychology and Nursing, as well as the Institutes of Human and Social Sciences, Education, Arts and Human Sciences, and part of the School of Engineering are established on the Gualtar campus, where there is also a set of services, such as a general library, several specialised libraries, a canteen, a university restaurant, seven cafeterias, a medical centre, a sports complex and two copy centres. It is the largest campus in terms of total implantation area (45 hectares), gross floor area $\left(152.115 \mathrm{~m}^{2}\right)$ and number of buildings (21). It is also the campus where the largest number of students attend their classes or other academic activities (approximately $2 / 3$ of the total number).

The Azurém Campus is located in Guimarães, next to the city's historical centre. The School of Engineering is located on this campus, where most of its study cycles are taught. The School of Architecture and some departments of the School of Sciences and of the Institute of Social Sciences are also on this campus. It also includes a set of services, such as a general library, several specialised libraries, a canteen, a grill, three 
cafeterias, a medical centre, a sports complex and a students' residence. It is the second largest campus in what concerns the total area of implantation (30 hectares), the gross floor area $(89.231 \mathrm{~m} 2)$ and the number of buildings (20).

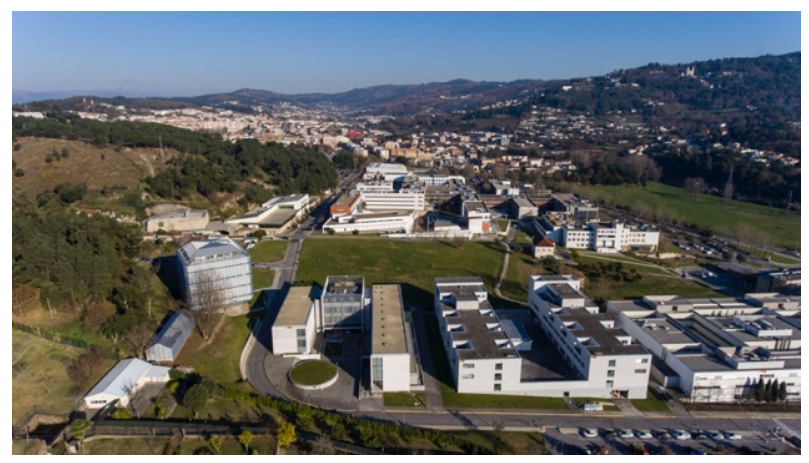

Fig. 1. The Gualtar Campus

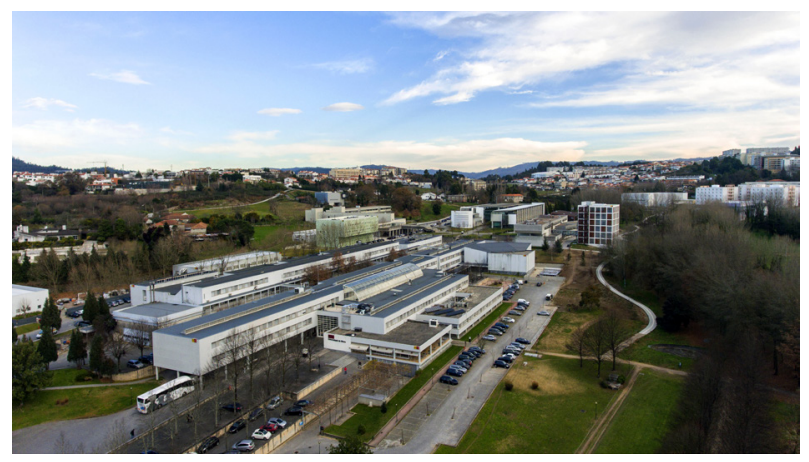

Fig. 2. The Azurém Campus

Couros is the southern area of the historic centre of Guimarães. In 1996 the Town Council of Guimarães initiated the rehabilitation of this industrial centre, and in 2001 the Multifunctional Complex of Couros was born. Within this context, and in order to strengthen UMinho's integration in the city, the Town Council of Guimarães and the University developed the Campurbis project (2006-2012). The intervention and rehabilitation of the former factories led to the creation of a new university space -the Couros campus- which, given its location on the city outskirts, emphasises the concepts of 'virtual campus' and 'university without walls', which are ingrained in UMinho's mission and strategy.

The infrastructure asset of the UMinho includes a significant number of buildings with quite diverse characteristics and ages and, consequently, significantly different maintenance needs.

\section{Building information modelling: a brief context in EU, Portugal and UMinho}

It is relevant to start contextualization with a definition of BIM, which briefly frames the topic for those not fully aware of its extent. According to the definition supported by UMinho [1], 'Building Information Modelling' is a methodology for information sharing and communication amongst all the stakeholders and during all the stages of the lifecycle of a given construction. It is normally supported by a digital model, accessible by software, which allows the virtual manipulation of the construction in concern. This digital model contains data about the geometrical features of the elements that compose the construction (e.g. beams, columns, electric plugs, installed equipment), as well as their properties and attributes, regardless of their nature, including physical properties, cost, construction timing, among others.

Even though BIM covers all stages of the lifecycle of construction, the scope of concern in this paper is the stage of operations and infrastructure management, normally termed as BIM-FM (Facilities Management) [2]. BIM-FM takes advantage of the extensive quantity and quality of information available in an as-built BIM model in order to assist operations and maintenance management of the building throughout its entire service life. The well-structured information available in the BIM Model can assist in several operational aspects simultaneously, such as: streamlined maintenance (e.g. through the integration of asset information and predictive/corrective work orders), improved space management, efficient use of energy (e.g. monitoring use of rooms/classrooms and even air conditioning or central heating), up-to-date available information for retrofits and renovations; enhanced lifecycle management (including improved prediction capacity of needs). Even though these aspects were already addressed by 'Computer Aided Facility Management' (CAFM) [3], their potential has been truly enlarged by BIM [4].

Nowadays, many world and chiefly EU countries have made BIM mandatory for their public procurement building projects, with private owners/investors following suit, the requirement for BIM usage and BIM experts is increasing dramatically. BIM progress can be felt strongest in northern and central EU countries which are rapidly developing their own BIM standards and specifications such as UK's BS and PAS documents while the European Committee for Standardization is promoting general CEN/TC 442 BIM standards. EU BIM awareness is further promoted by the EU BIM Task Group which is bringing together national efforts into a common and aligned European approach to develop a world-class digital construction sector.

Even though Portugal has not yet set out mandatory BIM use, there are many owners becoming aware of the inherent advantages and making BIM mandatory in their procurement processes. One of the main recent contributors for BIM adoption and spreading in Portugal is the National Technical Committee CT197 on BIM (www.ct197.pt, where UMinho has an active participation), which has successfully issued a BIM procurement guide (Employers Information Requirements) [5], and is currently finalizing the draft of a national BIM Execution Plan template.

It is also worth to mention the extensive experience of the Civil Engineering Department from UMinho in BIM, which was the first in Portugal to start teaching BIM as an independent Curricular Unit back in 
2012/2013, and continues today [6], in several study cycles. The UMinho also leads the National Course of Building Information Modelling at the National Engineers Association since 2014, with 6 successful past editions and more than 250 professionals trained (www.cursobim.com). Furthermore, the UMinho has hosted the first National Conference of Building Information Modelling PTBIM in November 2016, and it now leads the scientific committee of the $2^{\text {nd }}$ PTBIM to take place in May 2018.

\section{A strategic roadmap for BIM-FM implementation at UMinho}

The challenges and opportunities of bringing infrastructure management towards a fully digital BIM based approach are numerous. Firstly, it is essential to define information and details to be included in the models. After that, it is necessary to make the digital models of the buildings and infrastructures, potentially assisted by advanced techniques, such as laser scanning. This situation is being tackled with an ambitious full campus digitalization plan. The opportunities being brought by a database of materials used in the Campuses can also represent an important keystone at the level of the analysis of buildings from a lifecycle management point of view.

Therefore, bearing in mind the potential benefits and the hurdles to overcome in order to implement BIM in the operations of UMinho, a 36-month plan has been drafted, beginning during the first semester of 2018. The outline of the main stages of the process is given below.

\section{Stage 0 - Diagnosis and human resource assignment - M1-M3}

- Work meetings with the current Infrastructure Management team of UMinho, as to establish an accurate description of current procedures, available information, further needs, human and material resources, etc.

- Definition of potential needs to hire a person for the implementation stage (e.g. with a grant), or alternatively basing efforts on the currently existing staff at UMinho (situation in which the exclusive dedication of one staff member with BIM competences is necessary).

- Clear definition of a 33-month implementation plan, according to the diagnosis of challenges and resources (human and financial). The plan to be drafted will correspond to an adapted version of the ideas forwarded in Stages 1-4 of the current planning (shown below).

Stage 1 - Definition of modelling rules; preimplementation of pilot model - M4-M6

- Careful study of the guidelines to be applied in terms of surveying and modelling, as well as modelling software and 'Common Data Environment' definition.
- Final definition of the information required in the models, as well as the protocols for their visualization (in the case of non-specialists) and updating. Attention will be also driven to 'maintenance orders' and management of 'predictive/corrective maintenance', as well as stock management for quick intervention (e.g. lamps, projectors, etc.).

- Creation of a small pilot demonstrating model to show to all potential users, with a workshop to be held at M6.

\section{Stage 2 - Modelling 3 buildings together with practical implementation of BIM-FM - M7-M12}

- There will be selected three buildings to demonstrate the feasibility of the plans/discussions laid out in Stages 0-1.

- These models will begin to be used and tested since M8-M9, and thus difficulties and problems shall be identified. Consequently, improvements and adaptations will be made to FM procedures and the modelling rules themselves.

- Production of specific UMinho documentation for future reference:

- Drafting of the strategic BIM Plan for UMinho, with larger extent that BIM-FM alone

- Definition of relevant 'Employer Information Requirements' for procurement processes in new constructions to be built within UMinho (based on the documentation issued by CT197-BIM).

- UMinho BIM Guidelines for surveying and modelling BIM Management protocols

\section{Stage 3 - Integral modelling of UMinho Campuses and extension of procedures - M13- M24}

- Based on the rules and protocols defined in Stage 2, the modelling of all Buildings of Gualtar and Azurém Campuses will be promoted. Both internal and external resources will be deployed. The duration of this process will strongly depend on the human and financial resources that may be invested.

- Increase the possibilities of management and attaining added sustainability through pilot implementation of IoT sensor networks in key buildings (temperature, humidity, fire, presence) as to support the next steps of integrated digitization of the Campuses.

-Potentiate the possibilities of generalized use of the information contained in the BIM models through direct interfaces in webpages (e.g. management of room reservation, inventory inputs from users, etc.). This stage will request specific support of UMinho specialists in the fields of Computer Science and Information Systems.

- Internal training programmes to all relevant stakeholders within the UMinho community. Dissemination activities both within and outside UMinho. 


\section{Stage 4 - Consolidation and integrating demonstrators - M25-M36}

- Stage of demonstration of the integrated concepts, with close intervention and monitoring by all the stakeholders in the process. Definition of adaptations and improvements, as well as their implementation.

\section{Concluding remarks}

Based on the consistent background and knowledge that the UMinho has in 'Building Information Modelling', a practical roadmap towards the full BIM digitalization of the infrastructure management process has been described it this paper. Indeed, the integration of databases that the digital BIM model provides is likely to bring significant advantages over traditional processes of infrastructure management (even those supported in digital databases that are difficult to integrate). In fact, the cross-linking of information will provide unique opportunities on both day-to-day operations (e.g. situation reporting), but also on strategic planning of predictive maintenance and other features of infrastructure management.

After an initial diagnosis stage, the process of BIM implementation formally involves four stages related to the definition of modelling rules/requisites (Stage 1), the preparation of three prototype buildings to test the concepts (Stage 2), the enlargement/generalization of the process towards the Campuses of the UMinho (Stage 3) and a final stage of consolidation and improvements (Stage 4). The entire process is expected to take 36 months, which is a duration considered feasible for the ambitious goals that have been set.

\section{References}

1. Azenha, M., J.C. Lino, B. Caires, BIM in Civil Engineering: design and construction, Lecture notes (in Portuguese), Integrated Master in Civil Engineering, UMinho (2018)

2. Eastman, C., Teicholz, P., Sacks, R., Liston K., BIM Handbook: a guide to Building Information Modelling for Owners, Managers, Designers, Engineers and Contractors. John Wiley \& Sons, Inc. Hoboken, New Jersey USA (2011)

3. Roper, K., Payant, R., The Facility Management Handbook (4 ${ }^{\text {th }}$ Edition), McGraw-Hill Education (2014)

4. Teicholz, P., BIM for facility Managers, Wiley (2013)

5. Costa, A.A., Matos, B., Drumond, D., Rodrigues, I., Guia de Contratação BIM, CT197 BIM (2017)

6. Azenha, M. J.C. Lino, Couto, J.P., BIM Teaching Strategies in Civil Engineering at the UMinho, In: the Proceedings of EDUBIM 2017, CESI Centre de Paris-Nanterre (2017) 